\title{
PENERAPAN METODE PERBANDINGAN EKSPONENSIAL UNTUK PRIORITAS PEMBINAAN INDUSTRI KECIL MENENGAH (IKM)
}

\author{
Amelia $^{1)}$,Yogi Primadasa ${ }^{2}$ \\ ${ }^{1}$ Sistem Informasi, STMIK Bina Nusantara Jaya Lubuklinggau \\ Jalan Yos Sudarso No 97 A Kota Lubuklinggau, Sumatera Selatan \\ E-mail :amelia.persib09@gmail.com ${ }^{1)}$,vaniadrv12@gmail.com²),yogiak45@gmail.com ${ }^{3)}$
}

\begin{abstract}
Dinas Perdagangan dan Perindustrian Kota Lubuklinggau always strives to assist small and medium industry (IKM) on Lubuklinggau city in improving their industrial development through assistance in the form of aid such as machine aid, fund and marketing so priority of IKM development is important so that the assistance can be given to IKM really need it. In determining the priority of IKM development still has constraint that there is no system that can support in decision making process to determine which IKM has the right to be prioritized because it's only done by looking again at blanko pendataan IKM which have register and compare it to do the assessment. But the assessment process still use two criteria that is the use of machine and the number of workers considered not optimal so that given assistance is considered less precise then just weighing two criteria, the result obtained to be given to the head of devision to get decision is often less precise target. The solution to solve this problem is to build a decision support system for the determination priority of IKM coaching which later can help Dinas Perdagangan dan Perindustrian Kota Lubuklinggau in determining priority of IKM coaching for information generated
\end{abstract}

Keywords:MPE, SPK, IKM coaching

\begin{abstract}
Abstrak
Dinas Perdagangan dan Perindustrian Kota Lubuklinggau selalu berupaya untuk membantu Industri Kecil Menengah (IKM) di Kota Lubuklinggau dalam meningkatkan perkembangan industrinya melalui pembinaan berupa pemberian bantuan seperti bantuan mesin, dana, dan pemasarannya sehingga penentuan prioritas pembinaan IKM penting dilakukan agar bantuan tersebut dapat diberikan kepada IKM yang benar - benar membutuhkannya. Dalam penentuan prioritas pembinaan IKM masih memiliki kendala yaitu tidak adanya sistem yang dapat mendukung dalam proses pengambilan keputusan untuk menentukan IKM yang berhak untuk diprioritaskan karena hanya dilakukan dengan melihat kembali blanko pendataan IKM yang telah mendaftar dan membandingkannya untuk dilakukan penilaian. Namun proses penilaian masih menggunakan dua kriteria yaitu penggunaan mesin dan jumlah pekerja yang dinilai masih belum optimal sehingga bantuan yang diberikan dinilai kurang tepat maka hanya dengan menimbang dua kriteria itu saja, hasil yang didapat untuk diberikan kepada Kabid untuk mendapatkan keputusan seringkali kurang tepat sasaran. solusi untuk mengatasi permasalahan ini adalah dengan membangun sistem pendukung keputusan penentuan prioritas pembinaan IKM yang nantinya dapat membantu Dinas Perdagangan dan Perindustrian Kota Lubuklinggau dalam menentukan prioritas pembinaan IKM atas informasi yang dihasilkan.
\end{abstract}

Kata kunci:MPE, SPK, Pembinaan IKM

\section{Pendahuluan}

Jumlah IKM yang ada di Kota Lubuklinggau terus meningkat yang hingga saat ini telah mencapai \pm 700 IKM. Tentu dengan semakin banyaknya IKM di Kota Lubuklinggau maka akan semakin banyak pula IKM yang mendaftar untuk dibina. Pembinaan yang dilakukan oleh Dinas Perdagangan dan Perindustrian Kota Lubuklinggau berupa pemberian bantuan yang dibutuhkan oleh IKM seperti bantuan mesin, dana, dan pemasarannya. Sehingga penentuan prioritas pembinaan IKM penting dilakukan agar bantuan tersebut dapat diberikan kepada IKM yang benar - benar membutuhkannya. Dalam penentuan prioritas pembinaan IKM masih memiliki kendala yaitu tidak adanya suatu sistem yang dapat mendukung dalam proses pengambilan keputusan untuk menentukan IKM mana yang berhak untuk diprioritaskan. Proses

penentuan prioritas pembinaan IKM ini masih dilakukan dengan melihat kembali blanko pendataan IKM yang telah mendaftar sebelumnya, membandingkan blanko pendataan IKM yang satu dengan yang lainnnya untuk dilakukan penilaian. Namun proses penilaian tersebut masih menggunakan dua kriteria yaitu penggunaan mesin dan jumlah pekerja yang dinilai masih belum optimal karena IKM yang menggunakan sedikit mesin belum tentu memiliki kapasitas produksi yang tinggi, sama halnya dengan jumlah pekerja, IKM yang memiliki sedikit pekerja belum tentu penghasilan yang didapat juga rendah sehingga bantuan yang diberikan dinilai kurang tepat. 
Maka hanya dengan menimbang dua kriteria itu saja, hasil yang didapat untuk diberikankepada Kabid untuk mendapatkan keputusan seringkali kurang tepat sasaran. Agar nantinya hasil yang didapat tepat sasaran pihak Dinas Perdagangan dan Perindustrian Kota Lubuklinggau membutuhkan sebuah sistem yang dapat memberikan informasi dengan cepat mengenai IKM mana yang berhak mendapatkan prioritas pembinaan dengan menambah beberapa acuan kriteria untuk mengoptimalkan penilaian dalam penentuan prioritas pembinaan IKM. Berdasarkan uraian tersebut, maka penulis mengangkat judul Penerapan Metode Perbandingan Eksponensial Dalam Sistem Pendukung Keputusan Penentuan Prioritas Pembinaan Industri Kecil Menengah (IKM) Pada Dinas Pedagangan dan Perindustrian Kota Lubuklinggau.

\section{Tinjauan Pustaka}

\section{Pembinaan}

Dalam Nurman dan Nurmasari (2014), Moekidjat menyatakan bahwa yang dimaksud dengan pembinaan adalah segala usaha dan kegiatan mengenai perencanaan, pengorganisasian, pembiayayaan, penyusunan program, koordinasi pelaksanaan dan pengawasan sesuatu pekerjaan secara efektif dan efisien untuk mencapai tujuan dengan hasil semaksimal mungkin.[3]

\section{Industri Kecil Menengah (IKM)}

Berdasarkan Peraturan Menteri Perindustrian Republik Indonesia Nomor : 64/M-IND/PER/7/2016 Industri adalah seluruh bentuk kegiatan ekonomi yang mengolah bahan baku dan / atau memanfaatkan sumber daya industri sehingga menghasilkan barang yang mempunyai nilai tambah atau manfaat lebih tinggi, termasuk jasa industri. Industri kecil merupakan industri yang mempekerjakan paling banyak 19 (sembilan belas) orang tenaga kerja dan memiliki nilai investasi kurang dari Rp. 1.000.000.000,00 (satu milyar rupiah) tidak termasuk tanah dan bangunan tempat usaha. Industri menengah merupakan industri yang memperkerjakan paling sedikit 20 (dua puluh) orang tenaga kerja dan memiliki nilai investasi paling banyak Rp. 15.000.000.000,00 (lima belas milyar rupiah).[5]

\section{Sistem Pendukung Keputusan}

Menurut Panggabean (2016), Sistem

pendukung keputusan (decision support systems disingkat DSS) adalah bagian dari sistem informasi berbasis komputer termasuk sistem berbasis pengetahuan (manajemen pengetahuan) yang dipakai untuk mendukung pengambilan keputusan dalam suatu organisasi perusahaan atau lembaga pendidikan. Dapat juga dikatakan sebagai sistem komputer yang mengolah data menjadi informasi untuk mengambil keputusan dari masalah yang spesifik. [4]
Komponen - komponen Sistem Pendukung

Keputusan

Dalam Darmanto, dkk. (2016), Subakti menyatakan bahwa komponen sistem pendukung keputusan adalah :

a. Data Management (Manajemen Data)

Merupakan komponen SPK sebagai penyedia data bagi sistem, yang mana data disimpan dalam Database Management System (DBMS), sehingga dapat diambil dan diekstraksi dengan cepat.

b. Model Management (Manajemen Model) Melibatkan model finansial, statistikal, manajemen science, atau berbagai model kuantitatif lainnya, sehingga dapat memberikan ke sistem suatu kemampuan analistis, dan manajemen software yang diperlukan.

c. Communication (dialog subsistem)

User dapat berkomunikasi dan memberikan perintah pada SPK melalui subsistem ini. Ini berarti menyediakan antarmuka.

d. Knowledge Management (Manajemen Pengetahuan)

e. Subsistem optional ini dapat mendukung subsistem lain atau bertindak sebagai komponen yang berdiri sendiri.[1].

\section{Metode Perbandingan Eksponensial (MPE)}

Menurut Pratiwi (2016:109), Metode Perbandingan Eksponensial (MPE) merupakan salah satu metode untuk menentukan urutan prioritas alternatif keputusan dengan kriteria jamak. Pada prinsipnya metode ini merupakan metode skoring terhadap pilihan yang ada. Dengan perhitungan secara eksponensial, perbedaan nilai antar kriteria dapat dibedakan tergantung kepada kemampuan orang yang menilai. Teknik ini digunakan untuk membantu individu pengambil keputusan untuk menggunakan rancang bangun model yang terdefinisi dengan baik pada tahapan proses. MPE akan menghasilkan nilai alternatif yang perbedaannya lebih kontras.Langkah - langkah yang perlu dilakukan dalam pemilihan keputusan dengan menggunakan MPE adalah :

1. Menyusun alternatif - alternatif keputusan yang akan dipilih.

2. Menentukan kriteria atau perbandingan relatif kriteria keputusan yang penting untuk dievaluasi dengan menggunakan skala konversi tertentu sesuai dengan keinginan pengambil keputusan.

3. Menentukan tingkat kepentingan relatif dari setiap kriteria keputusan atau pertimbangan kriteria. Penentuan bobot ditetapkan pada setiap kriteria untuk menunjukkan tingkat kepentingan suatu kriteria.

4. Melakukan penilaian terhadap semua alternatif pada setiap kriteria bentuk total skor tiap alternatif.

5. Menghitung skor atau nilai total setiap alternatif dan mengurutkannya. Semakin besar Total Nilai 
(TN) alternatif maka semakin tinggi urutan prioritasnya.

Formulasi perhitungan total nilai setiap pilihan keputusan adalah sebagai berikut :

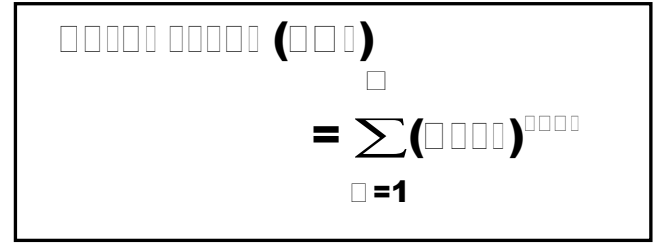

$$
\begin{array}{ll}
\text { Tni } & =\text { Total nilai alternatif ke-i } \\
\text { Rkij } & =\text { Derajat kepentingan relatif kriteria } \\
& \text { ke-j pada pilihan keputusan } \mathrm{i} \\
\mathrm{TKK} \mathrm{j} & =\text { Derajat kepentingan kriteria } \\
& \text { keputusan ke-j; TKK } \mathrm{j}>0 \text {; bulat } \\
\mathrm{n} & =\text { Jumlah pilihan keputusan } \\
\mathrm{m} & =\text { Jumlah kriteria keputusan }[6]
\end{array}
$$

\section{Metodologi Penelitian}

Berdasarkan analisis masalah, diketahui bahwa penentuan prioritas pembinaan IKM merupakan hal yang penting dilakukan agar bantuan dalam pembinaan dapat diberikan kepada IKM yang benar - benar membutuhkannya. Namun didalam penentuan prioritas pembinaan IKM hanya menggunakan dua kriteria yaitu penggunaan mesin dan jumlah pekerja yang dinilai masih belum optimal karena IKM yang menggunakan sedikit mesin belum tentu memiliki kapasitas produksi yang tinggi, sama halnya dengan jumlah pekerja, IKM yang memiliki sedikit pekerja belum tentu penghasilan yang didapat juga rendah sehingga bantuan yang diberikan dinilai kurang tepat. Maka hanya dengan menimbang dua kriteria itu saja, hasil yang didapat untuk diberikan kepada Kabid untuk mendapatkan keputusan seringkali kurang tepat sasaran. Maka penulis menambahkan tiga kriteria antara lain kriteria penghasilan, kapasitas produksi, dan izin usaha.Penambahan kriteria penghasilan dan izin usaha berdasarkan hasil analisa penulis dari kuisioner yang diisi sendiri oleh IKM, untuk kriteria kapasitas produksi didapat dari studi pustaka yang penulis lakukan, dimana penulis menggunakan jurnal - jurnal untuk memilih dan mempertimbangkan kriteria ini, maka penulis membantu Dinas Perdagangan dan Perindustrian Kota Lubuklinggau dalam menentukan prioritas pembinaan IKM dengan membangun sebuah sistem pendukung keputusan penentuan prioritas pembinaan IKM dengan menggunakan metode perbandingan eksponensial berdasarkan lima kriteria tersebut.

Flow Diagram SPK Prioritas Pembinaan IKM

(i)

Data Flow Diagram Level 1
Gambar 1. Flow Diagram SPK Prioritas IKM

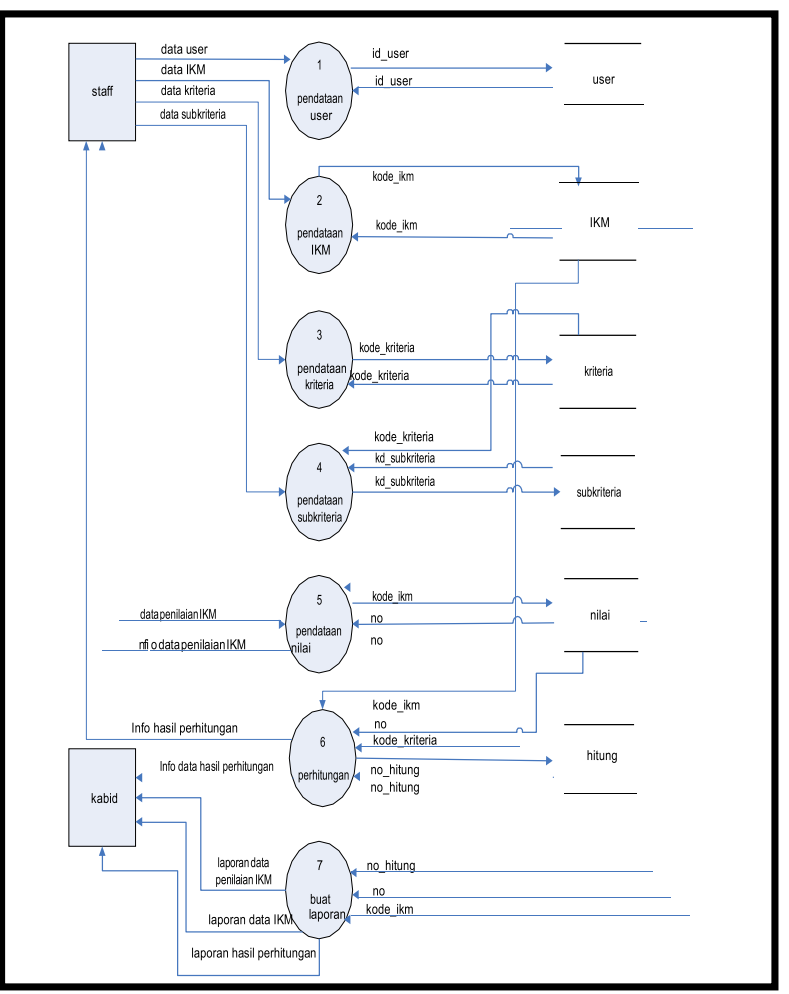




\section{Hasil dan Pembahasan}

Dari hasil analisa dengan metode yang digunakan dihasilkan system pendukung keputusan pengelolaan prioritas pembinaan IKM seperti pada gambar 3, 4 dan 5 dibawah ini :

\section{Form Proses SPK}

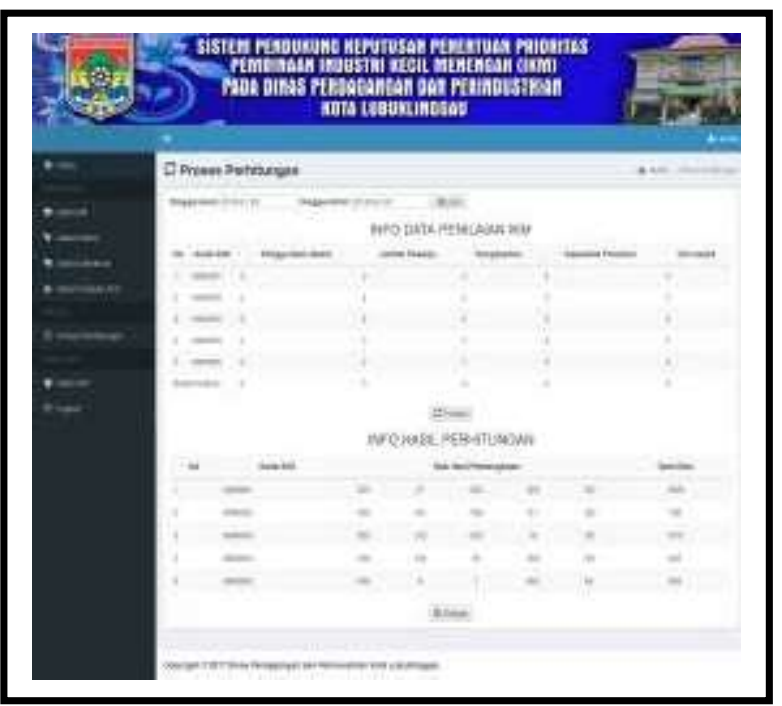

Gambar 3. Proses SPK

Tahapan ini proses pendataan semua kriteria dan alternative yang akan di hitung dengan menggunakan system memalui persamaan metode perbandingan eksopnsial.

\section{Form Penilaian IKM}

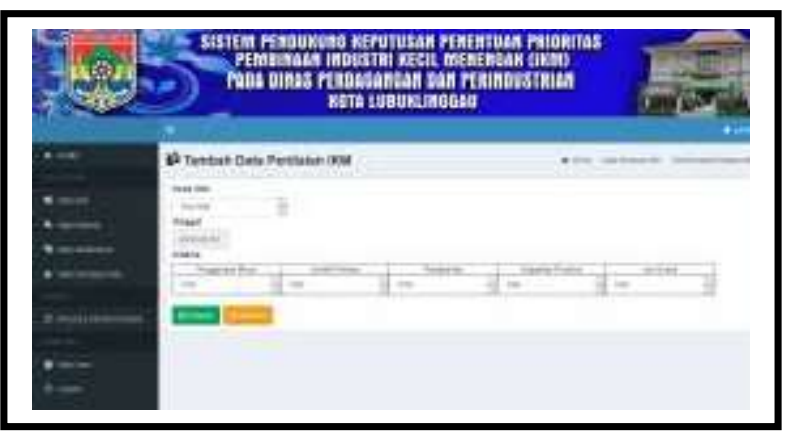

Gambar 4. Form Penilaian IKM

Selanjutnya tahapan penilaian dilakukan terhadap alternatif yang ada dengan nilai bobot sesuai dengan kriteria untuk menghasilkan alternative yang layak untuk mendapatkan prioritas pembinaan.

\section{Hasil Penilaian}

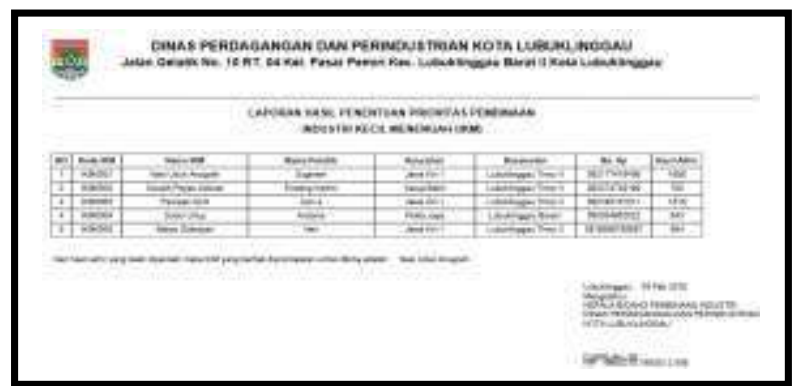

Gambar 5. Hasil Penilaian dengan SPK

\section{Kesimpulan}

\subsection{Simpulan}

Berdasarkan dari uraian dan analisa yang telah dilakukan, maka penulis mengambil beberapa kesimpulan yaitu :

1. Penelitian menghasilkan sebuah Sistem Pendukung Keputusan Penentuan Prioritas Pembinaan Industri Kecil Menengah (IKM) Pada Dinas Perdagangan dan Perindustrian Kota Lubuklinggau dan setelah dicoba, dengan sistem ini dapat dicari IKM yang akan diprioritaskan untuk dibina.

2. Setelah sistem pendukung keputusan ini berhasil dibuat, penulis melakukan perbandingan antara perhitungan manual dengan perhitungan sistem yang telah dibuat dengan 5 alternatif yaitu nasi uduk anugrah, keripik peyek adinda, pempek GLN, dodol uhuy dan bakso silampari yang diperoleh dari data industri minggu pertama pada bulan desember 2017 dan hasil dari perbandingan tersebut adalah nilai yang dihasilkan oleh sistem pendukung keputusan ini memiliki nilai yang sama dengan nilai perhitungan manual dimana IKM Nasi Uduk Anugrah adalah IKM yang berhak mendapatkan prioritas pembinaan dengan nilai tertinggi, sehingga dapat disimpulkan bahwa sistem pendukung keputusan yang telah dibuat ini dapat membantu Kabid dalam menentukan prioritas pembinaan IKM dengan cepat dan tepat berdasarkan perhitungan yang akurat

3. Sistem pendukung keputusan yang telah dihasilkan ini diterapkan dengan lima kriteria yang menjadi acuan dalam mempertimbangkan keputusan. Lima kriteria tersebut tiga diantaranya ditambahkan oleh penulis berdasarkan teknik analisa dari hasil kuisioner dan studi pustaka 


\subsection{Saran}

Beberapa saran yang dapat penulis sampaikan pada akhir dari penelitian ini adalah :

1. Bagi peneliti yang akan mengembangkan Sistem Pendukung Keputusan Penentuan Prioritas Pembinaan Industri Kecil Menengah (IKM) diharapkan dapat membuat laporan data IKM dalam bentuk grafik sehingga dapat mempermudah Kabid untuk mengetahui perkembangan IKM yang mendaftar untuk dilakukan pembinaan di setiap minggu nya.

2. Dalam memecahkan permasalahan ini, metode perbandingan eksponensial (MPE) bukanlah satu satu nya metode yang digunakan dalam pengambilan keputusan, namun alangkah baiknya jika metode perbandingan eksponensial ini digabungkan dengan metode lain agar mendapatkan hasil yang lebih efektif.

\section{Daftar Rujukan}

[1] Darmanto, E., Latifah, N. dan Susanti, N., 2014, Penerapan Metode AHP (Analythic Hierarchy Process) Untuk Menentukan Kualitas Gula Tumbu, Jurnal Simetris, No.1, Vol.5, ISSN 22524983, Halaman 75-82

[2] Munawaroh, E., Destiani, D. dan Supriatna, A.D., 2013, Perancangan Aplikasi Rekam Medis Klinik Bersalin Baiturrahman Menggunakan Metode Object Oriented, Jurnal Algoritma Sekolah Tinggi Teknologi Garut, Vol.10, ISSN 23027339, Halaman 1-10

[3] Nurman dan Nurmasari, 2014, Efektivitas Pembinaan Pegawai Pada Kantor Badan Kepegawaian Daerah Di Kabupaten Bengkalis, Jurnal RAT, No.1, Vol.3, Halaman 418-423

[4] Panggabean, E., 2016, Sistem Pendukung Keputusan Evaluasi Kinerja Dosen Menggunakan Metode Fuzzy Simple Additive Weighting (FSAW), Jurnal Mantik Penusa, No.1, Vol.19, ISSN 2088-3943

[5] Peraturan Menteri Perindustrian Republik Indonesia Nomor 64 Tahun 2016 Tentang Besaran Jumlah Tenaga Kerja dan Nilai Investasi Untuk Klasifikasi Usaha Mandiri, Jakarta

[6] Pratiwi, H., 2016, Buku Ajar Sistem Pendukung Keputusan, Deepublish, Yogyakarta.

[7] Retnosari, D., 2013, Penyandian File Gambar Dengan Metode Substitusi Dan Transportasi Serta Implementasinya Menggunakan Bahasa Pemograman Borland Delphi 7.0, Jurnal Info Teknik, No.2, Vol.14, Halaman 103-113

[8] Rosa, A.S. dan M.Shalahuddin, 2013, Rekayasa Perangkat Lunak Terstruktur dan Berorientasi Objek, Informatika, Bandung

[9] Sidik, B., 2014, Pemograman Web PHP, Informatika, Bandung
[10]Supriyanto, T. dan Amalia, R., 2016, Sistem Administrasi Proses Belajar Mengajar Di Program Studi Teknik Telekomunikasi PNJ Berbasis Android dengan Transmisi Wifi, Jurnal Ilmiah SETRUM, No.1, Vol.5, ISSN 2301-4652, Halaman 43-46 